\title{
Growth curves and their implications in hand-fed Monk parrots (Myiopsitta monachus)
}

This article was published in the following Dove Press journal:

Veterinary Medicine: Research and Reports

15 October 2015

Number of times this article has been viewed

\author{
Christina Petzinger ${ }^{1,2}$ \\ J Jill Heatley ${ }^{3}$ \\ John E Bauer ${ }^{1,2}$ \\ 'Comparative Animal Nutrition \\ Research Laboratory, Department \\ of Small Animal Clinical Sciences, \\ College of Veterinary Medicine and \\ Biomedical Sciences, IIntercollegiate \\ Faculty of Nutrition, Texas A\&M \\ University, ${ }^{3}$ Zoological Medicine \\ Service, Department of Small Animal \\ Medicine and Surgery, College of \\ Veterinary Medicine and Biomedical \\ Sciences, Texas A\&M University, \\ College Station, TX, USA
}

Correspondence: J Jill Heatley Zoological Medicine Service, Department of Small Animal Medicine and Surgery, College of Veterinary Medicine and Biomedical Sciences, Texas A\&M University, Mail Stop 4474, College Station, TX 77843-4474, USA

Tel + I 979845 I202

Email jheatley@cvm.tamu.edu
Abstract: Monk parrots (Myiopsitta monachus) were hand-fed over two chick seasons spanning of 2010 to 2011. Information from the growth curve of chicks hand-fed in 2010 was used to develop a feeding protocol for the 2011 season (Protocol-2011). This protocol addressed the problems of delayed followed by excessive growth experienced by parrots hand fed in 2010 . Monk parrots that were hand-fed in 2011 following the new protocol experienced delayed growth after 20 days of age. However, some Monk parrots were fed in excess of Protocol-2011 and did not experience a major delay in growth. The energy requirement equations used to construct Protocol-2011 were low when compared to adult Monk parrot maintenance energy requirements. The data suggest that growing birds do not require approximately twice their adult maintenance energy requirements, as is the case for growing dogs. Additionally, there appear to be fluctuations in energy needs as Monk parrots grow. A major increase in energy needs occurred between days 18 and 23 posthatching, which corresponds to feather development and growth in Monk parrot chicks. Thus, multiple equations estimating energy requirements, rather than just one equation, are likely needed from hatching to fledging in order to ensure adequate energy is provided to chicks. More research on the energy requirements of growing Monk parrots, especially around the time of fledging and weaning, is needed to improve hand-fed methods and potentially the adult health of hand-fed birds.

Keywords: psittacine, energy requirement, Quaker parrot, hand feeding, chick, hand-fed

\section{Introduction}

Monk parrots (Myiopsitta monachus) originate from South America and have established numerous feral populations throughout the United States. These parrots are also commonly kept as pets due to their small size and mimicking abilities. Monk parrots are commonly referred to as Quaker parrots or Monk parakeets. Monk parrots weigh around $100 \mathrm{~g}$, build their nests communally, and have a clutch size of five to nine eggs. ${ }^{1}$ Monk parrot chicks fledge around day 40 posthatching. ${ }^{2}$

The maintenance energy requirements of most parrot species have not been fully established. Most research on energy requirements in birds has focused on poultry, especially chickens (Gallus gallus domesticus), as well as budgerigars (Melopsittacus undulatus). ${ }^{3}$ Information on poultry can be limiting as poultry species are precocial whereas parrots are altricial. Additionally, research in poultry species focuses on maximizing the growth rate for meat production, which is undesirable for pets and conservation purposes. While there is information on budgerigars, these birds are one of the smallest parrot species and may thus differ in energy requirements in terms of body mass from larger parrot species. The growing energy requirements of larger parrots 
has been studied even less, although it can be estimated from the adult maintenance energy requirements, as is done with domestic dogs and cats. ${ }^{4}$

Hand-feeding of birds is commonly performed by pet bird breeders, zoological institutions, and rescue/rehabilitation facilities, which establish individualized methods based on years of experience and previous success. ${ }^{5}$ This methodology, however, does not ensure that the birds will achieve optimal health as adults. While the established methods result in the birds living to adulthood, they may lead to detrimental phenotypic effects in adults or excess body fat in weanlings. Many chronic, progressive inflammatory diseases, including atherosclerosis, are linked to excess body fat. To help improve bird health, it is important to determine the energy requirements of adult and growing birds of many species and to ensure public access to this information.

\section{Methods}

\section{0 hand-fed birds}

A number of feral Monk parrots ranging in age from embryos to nestlings were donated to the Schubot Exotic Bird Health Center at Texas A\&M University (College Station, TX, USA) during the summer of 2010 based on research on this species regarding appropriate deterrents from electrical structures. All birds were captured, raised, and maintained in Schubot aviaries in accordance with multiple Institutional Animal Care and Use Committee Protocols approved by Texas A\&M University. Recommendations and methods for hand-fed parrot chicks were sought from established breeders and researchers (Cornejo et al, unpublished data, 2009), as well as from feed manufacturers. ${ }^{6}$ Because protocols for hand-fed Monk parrots specifically had not been established, feedings based on general guidelines were employed. Briefly, this consisted of feeding commercial formulas either by tube or syringe until the crop appeared full. All chicks were fed the same commercial hand-feeding formulas. Feed volumes, as a percentage of body mass, known to be safe for chicks at varying ages were employed as guidelines. ${ }^{6}$ The crop was kept full during the day. However, crops were checked to ensure complete emptying overnight, unless the bird was under 10 days of age.

\section{II hand-fed birds}

Additional feral Monk parrots ranging in age from embryos to early fledglings were donated to the Schubot Exotic Bird Health Center at Texas A\&M University during late spring and summer, 2011. In an attempt to prevent potential health issues from delayed growth followed by catch-up growth experienced by the birds hand-fed in 2010, the energy requirements of growing Monk parrots were estimated to establish a protocol for hand-fed chicks during 2011 (Table 1). The energy requirements of growing Monk parrots were estimated by doubling a previously published existence energy requirement equation (kilocalorie per day) of nonpasserine birds:

$$
\left(0.5404 * \mathrm{~W}^{\wedge} 0.7545, \mathrm{~W}=\mathrm{g}\right)^{7}
$$

and one for mammals:

$$
\left(110 * \mathrm{~W}^{\wedge} 0.75, \mathrm{~W}=\mathrm{kg}\right)^{4}
$$

A similar strategy has been recommended for small mammals including growing canine species. ${ }^{4}$ The metabolizable energy content of the selected commercially available hand-feeding formulas was estimated by calculation from the guaranteed analysis. The estimated metabolizable

Table I Feeding protocol for 201 I hand-fed Monk parrots

\begin{tabular}{lllll}
\hline Age (days) & Body weight $(\mathbf{g})$ & Volume per feeding & Formula to water $(\mathrm{kcal} / \mathrm{mL})$ & Feeding times \\
\hline $0-4$ & $5-9$ & $0.3-0.7 \mathrm{~mL}$ & $\begin{array}{l}\text { One part formula A: three parts } \\
\text { water }(1.0 \mathrm{kcal} / \mathrm{mL})\end{array}$ & $\begin{array}{l}3 \mathrm{am}, 6 \mathrm{am}, 8 \mathrm{am}, 10 \mathrm{am}, 12 \mathrm{pm}, 2 \mathrm{pm}, \\
4 \mathrm{pm}, 6 \mathrm{pm}, 8 \mathrm{pm}, 10 \mathrm{pm}, 12 \mathrm{am}\end{array}$ \\
$5-8$ & $10-15$ & $0.5-1 \mathrm{~mL}$ & $\begin{array}{l}\text { One part formula A: two parts } \\
\text { water }(1.3 \mathrm{kcal} / \mathrm{mL})\end{array}$ & $\begin{array}{l}6 \mathrm{am}, 8 \mathrm{am}, 12 \mathrm{pm}, 2 \mathrm{pm}, 4 \mathrm{pm}, 6 \mathrm{pm}, \\
8 \mathrm{pm}, 10 \mathrm{pm}, 12 \mathrm{am}\end{array}$ \\
$9-21$ & $20-50$ & $2-5 \mathrm{~mL}$ & $\begin{array}{l}\text { One part formula B: three parts } \\
\text { water }(0.82 \mathrm{kcal} / \mathrm{mL})\end{array}$ & $6 \mathrm{am}, 9 \mathrm{am}, 12 \mathrm{pm}, 3 \mathrm{pm}, 7 \mathrm{pm}, 10 \mathrm{pm}$ \\
$22-40$ & $60-80$ & $6-8 \mathrm{~mL}$ & $\begin{array}{l}\text { One part formula B: two parts } \\
\text { water }(1.1 \mathrm{kcal} / \mathrm{mL})\end{array}$ & $6 \mathrm{am}, 10 \mathrm{am}, 2 \mathrm{pm}, 6 \mathrm{pm},(10 \mathrm{pm})$ \\
$41-60$ & $90-120$ & $\begin{array}{l}\text { One part formula B: two parts } \\
\text { water }(1.1 \mathrm{kcal} / \mathrm{mL})\end{array}$ & $\begin{array}{l}6 \mathrm{am}, 10 \mathrm{am}, 2 \mathrm{pm},(8 \mathrm{pm}) \\
\text { offer weaning foods }\end{array}$ \\
\hline
\end{tabular}

Notes: Commercially available diets were used for this protocol. Feed dilution and number of feedings were calculated to meet the estimated energy requirements of the growing Monk parrots using the estimated calories of the chosen commercial diets. Feeding times in parenthesis indicate an optional feeding which may be given to birds if their crops were not full and the bird was showing signs of hunger. Formula A represents Harrison's Neonatal Formula , Formula B represents Zupreem Embrace Plus. Volume per feeding was estimated from percent of body weight that can be safely fed to baby birds. ${ }^{5}$ 
energy content was used in conjunction with known safe volumes per feeding (percent of body mass) (Cornejo et al, unpublished data, 2009), to determine the number of feedings required to meet the estimated daily energy requirements of the growing Monk parrots. The desired feed dilutions for providing necessary water in addition to ease of feeding were also considered in the calculations. All chicks were fed the same commercial hand-feeding formulas via either tube or syringe. The amount of feed offered was determined by body mass following the protocol in Table 1 (Protocol-2011). The ages of the birds were estimated from their individual body masses on the first full day of Schubot Exotic Bird Health Center possession using data from the 2010 hand-fed birds and parent-reared Monk parrots. ${ }^{1}$ Because there were a large number of birds, they were divided into four smaller groups consisting of three to eight birds identified by black, pink, green or red dots. Subgrouping was based on body mass and stage of development at the time of acquisition.

All statistics were analyzed using JMP 9.0.3 (SAS Institute Inc., Cary, NC, USA) with $P<0.05$ considered as statistically significant. Data were analyzed for normality using the Shapiro-Wilk test. Peak body mass prior to fledging and age at peak body mass were analyzed using one-way analysis of variance with Tukey-Kramer as a post hoc test.

\section{Results}

\section{0 hand-fed birds}

In 2010, our hatchling parrot survival rate was poor: of four nestlings and eleven eggs intaken, only six fledged. Necropsy records for juvenile Quaker parrots from 2010 were available for three birds. All birds lacked gross lesions, but two birds had histopathologic lesions of nephrosis, multifocal bacterial epidermitis, and subcutaneous edema, and one bird had findings consistent with sepsis. Based on the likelihood of the intake of additional birds requiring hand feeding the following year, growth curves for the 2010 group were compared to a previously published growth curve for parentreared Monk parrots (Figure 1). ${ }^{1}$ Data were thus obtained on seven Monk parrots during growth; however, only five survived past fledging. Figure 1 illustrates a delay in growth of the hand-fed birds occurring up to approximately day 28 posthatching. Birds then experienced a rapid period of catchup growth and continued to grow, leading to significantly higher peak body masses prior to fledging as compared to parent-reared birds (Table 2; $121.2 \mathrm{~g}$ hand-fed versus $97.7 \mathrm{~g}$ parent-raised). ${ }^{1}$ Hand-fed birds also experienced delayed fledging and weaning times. Additionally, stepwise body

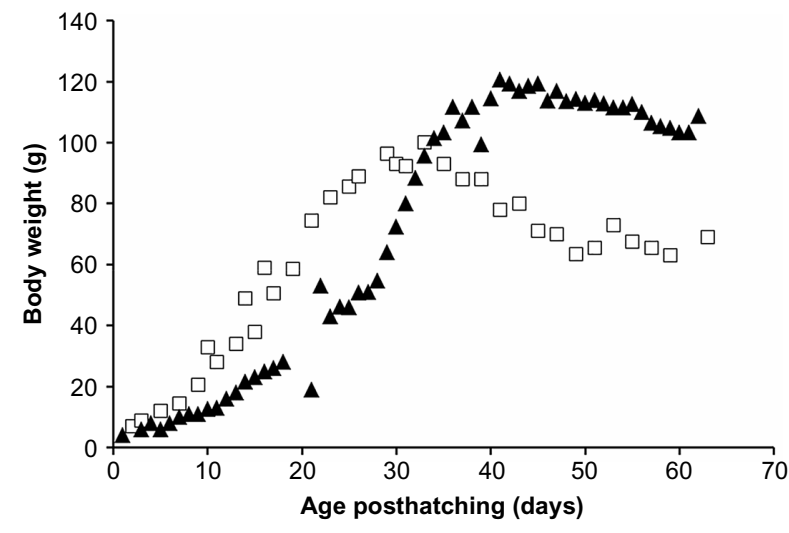

Figure I Growth curves for Monk parrots hand-fed by the Schubot Exotic Bird Health Center (Texas A\&M University, College Station, TX, USA).

Notes: Filled triangles represent Monk parrots hand-fed in 20I0, and open squares represent those that were parent-raised. Adapted from Caccamise DF, Alexandro PJ. Growth rate in the Monk parakeet. Wilson Journal of Ornithology. 1976;88(3):495-497.'

mass loss patterns were seen near the time of fledging in hand-fed birds compared to continuous body mass loss in parent-reared birds. ${ }^{1}$

\section{I hand-fed birds}

In 2011, Schubot aviaries accepted over 30 hatchling Monk parrots and only a single bird died. Necropsy was not performed on this bird. Data were obtained from 18 hand-fed Monk parrots. The growth curves for the four groups were compared to the 2010 hand-fed and the parent-reared Monk parrots (Figure 2). Two of the subgroups (black dot [number $\{n\}=6]$ and green $\operatorname{dot}[\mathrm{n}=3]$ ) closely followed the parent-reared birds while two subgroups (pink dot $[n=6]$ and red dot $[n=4]$ ) diverged to a slower growth rate around day 20. The growth curve for the average of all chicks hand-fed in 2011 closely followed that of the parent-reared chicks up to approximately day 30 posthatching (Figure 3 ).

The peak body mass prior to fledging and the age to reach peak body mass was compared from the 2010 handfed birds and the parent-reared birds (Table 2). ${ }^{1}$ There was no significant difference in peak body mass prior to fledging between any of the subgroups hand-fed in 2011 and the chicks hand-fed in 2010. Chicks hand-fed in 2010 and the green dot subgroup from 2011 reached significantly higher peak body masses than did parent-reared birds. The age to reach peak body mass was not significantly different between the pink dot subgroup, red dot subgroup, and the 2010 handfed birds. However, these three groups did take significantly longer than the parent-reared birds and the black dot and green dot subgroups to reach peak body mass. There was no statistically significant difference in age at peak body mass 
Table 2 Growth rate indicators in Monk parrots hand-fed at Schubot Exotic Bird Health Center (Texas A\&M University, College Station, TX, USA) compared to parent-raised Monk parrots

\begin{tabular}{lllllll}
\hline Number of observations & $\begin{array}{l}\text { Black dot } \\
(\mathbf{n = 6})\end{array}$ & $\begin{array}{l}\text { Green dot } \\
(\mathbf{n}=\mathbf{3})\end{array}$ & $\begin{array}{l}\text { Pink dot } \\
(\mathbf{n}=\mathbf{6})\end{array}$ & $\begin{array}{l}\text { Red dot } \\
(\mathbf{n = 3})\end{array}$ & $\begin{array}{l}\text { Hand-fed 2010 } \\
(\mathbf{n}=\mathbf{7})\end{array}$ & $\begin{array}{l}\text { Parent-raised } \\
(\mathbf{n}=\mathbf{3})\end{array}$ \\
\hline Peak weight prefledging $(\mathrm{g})^{*}$ & $113.0^{\mathrm{a}, \mathrm{b}}$ & $125.0^{\mathrm{a}}$ & $112.0^{\mathrm{a}, \mathrm{b}}$ & $105.7^{\mathrm{a}, \mathrm{b}}$ & $121.2^{\mathrm{a}}$ & $97.7^{\mathrm{b}}$ \\
Age at peak weight (days) ${ }^{* *}$ & $34.3^{\mathrm{c}}$ & $34.0^{\mathrm{b}, \mathrm{c}}$ & $40.8^{\mathrm{a}, \mathrm{b}}$ & $45.3^{\mathrm{a}}$ & $42.8^{\mathrm{a}}$ & $29.3^{\mathrm{c}}$ \\
\hline
\end{tabular}

Notes: Letters that differ across rows $(\mathrm{a}, \mathrm{b}, \mathrm{c})$ are significantly different $(P<0.05)$. Colored dot labels are the subgroups of birds hand-fed in $20 \mathrm{I}$ I. $* P=0.0 \mathrm{I} 6$; $* * P<0.000 \mathrm{I}$. Adapted from Caccamise DF, Alexandro PJ. Growth rate in the Monk parakeet. Wilson Journal of Ornithology. 1976;88(3):495-497.'

Abbreviation: $\mathrm{n}$, number.

between the parent-reared chicks and the black dot and green dot subgroups.

\section{Discussion}

\section{0 hand-fed birds}

Delayed growth experienced by the 2010 hand-fed birds may be associated with delayed motor development. Compensatory growth following a period of stress (nutritional stress in this case) may be a strategy used to minimize future detrimental growth effects on phenotype or fitness. ${ }^{8}$ However, this strategy will not prevent the occurrence of all detrimental effects, with some appearing later in life. ${ }^{9}$ Furthermore, the period of rapid body mass increase may also lead to health issues and phenotypic alterations later in life. For example, excess body mass gain prior to fledging, and beginning their adult life weighing more than parent-reared birds ${ }^{1}$, could potentially increase their risk of developing atherosclerosis and other chronic, progressive inflammatory diseases as adults. A reduction in body mass after obtaining peak body weight was also observed in Song sparrows (Melospiza melodia).${ }^{10}$ However, Song sparrows that were not feed-restricted lost four times as much body mass as the sparrows that were restricted to $60 \%$ of the controls' intake. ${ }^{10}$ Thus a reduction in the amount of body mass

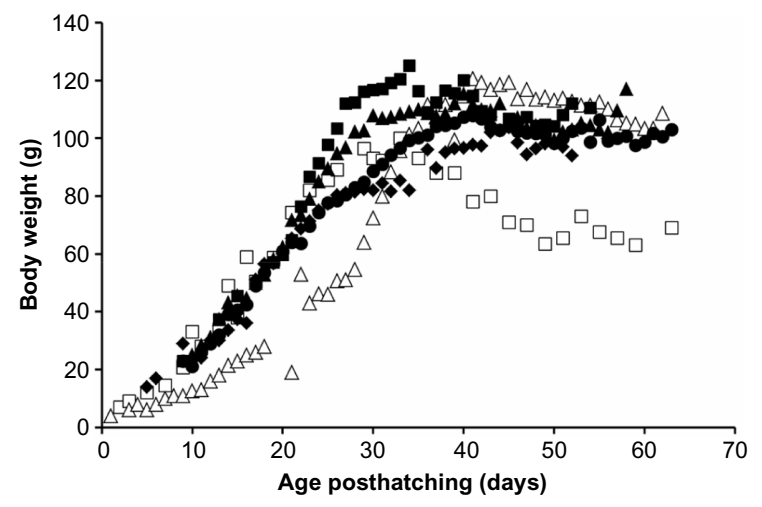

Figure 2 Average growth curves for subgroups of Monk parrots raised at the Schubot Exotic Birds Health Center in 2010 and 2011.

Notes: The birds hand-fed in $201 \mathrm{I}$ were split into four groups: black dot (filled triangles); pink dot (filled circles); green dot (filled squares); and red dot (filled diamonds). Open triangles represent birds hand-fed in 2010. Open squares are birds that were parent-raised. Adapted from Caccamise DF, Alexandro PJ. Growth rate in the Monk parakeet. Wilson Journal of Ornithology. 1976;88(3):495-497.' lost following obtaining peak body mass may reduce the detrimental effects of nutritional stress. However, Ricklefs ${ }^{11}$ reported that the body mass loss experienced by nestlings immediately prior to fledging is associated with a decrease in water content, while total lean dry mass and lipid content remain constant. Thus, excess lipid accumulation during growth is not significantly lost prior to adulthood, and body composition may differ between birds of the same species that lose varying amounts of body mass after obtaining peak body mass. The higher peak body mass observed for chicks hand-fed in 2010 versus parent-reared chicks, in addition to retaining that body mass, likely represents larger fat stores (and water) retained into adulthood for the chicks hand-fed in 2010. Obesity in human infants has recently been associated with delayed motor development, and it may have a similar effect in Monk parrots if they become overweight when young. Slining et $\mathrm{al}^{12}$ and Nowicki et $\mathrm{al}^{13}$ found that early nutritional stress affects brain growth and song-learning abilities in Swamp sparrows (Melospiza. georgiana). Based on the multitude of potential health issues that may result from an excessive growth rate and/or excessive body mass gain when young, research should focus on the nutritional requirements and methods of hand-fed Monk parrots in order to prevent the development of these conditions. While

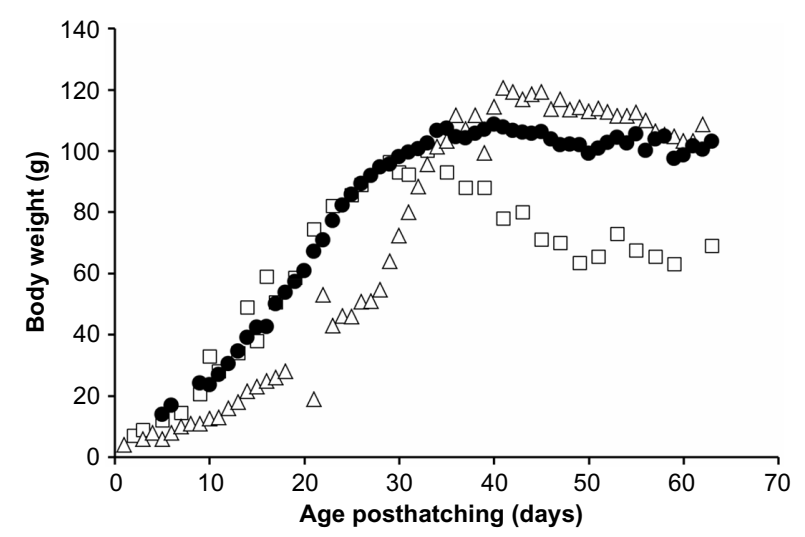

Figure 3 Average growth curves for Monk parrots raised at the Schubot Exotic Bird Health Center in 2010 and $201 \mathrm{I}$.

Notes: Filled circles represent Monk parrots hand-fed in 2011. Open triangles represent birds hand-fed in 2010. Open squares are birds that were parent-raised. Adapted from Caccamise DF, Alexandro PJ. Growth rate in the Monk parakeet. Wilson Journal of Ornithology. 1976;88(3):495-497.' 
protein requirements are important and should be met, energy requirements must be studied to prevent under- or over-energy consumption in growing chicks, which could also result in adverse health effects.

\section{II hand-fed birds}

Analysis of the energy intake of the four subgroups hand-fed in 2011 revealed that the pink dot and red dot birds were fed according to Protocol-2011, as shown in Table 1. The black dot and green dot subgroups received more kilocalories per day than Protocol-2011 called for beginning around day 20 . Since the black dot and green dot subgroups closely followed the growth curve of the parent-reared Monk parrots up to 30 days of age, it can be concluded that the twofold increase of the adult existence energy equation for nonpasserines ${ }^{7}$ originally estimated as the chicks' energy needs per day - was lower than their actual requirements.

To better understand why the equations used underestimated the kilocalorie energy requirements per day of growing Monk parrots, the energy intake of adult Monk parrots maintaining body mass and housed at the Schubot Exotic Bird Health Center ${ }^{14}$ were compared to the nonpasserine existence energy requirement equation. ${ }^{7}$ Adult Monk parrots maintaining their body mass consumed 1.87 times more kilocalories of energy per day than was estimated by Kendeigh's equation.? A comparison was then made between the energy intake of the birds hand-fed in 2011 to the modified equation for the adult Monk parrot maintenance energy requirement:

$$
\left(1.87 * 0.5404 * \mathrm{~W}^{\wedge} 0.7545 \mathrm{kcal} \text { per day, } \mathrm{W}=\mathrm{g}\right)
$$

(Figure 4). On first observation, it appeared that hand-fed chicks consumed 1.4 times the adult Monk parrot maintenance energy requirement:

$$
\left(1.43 * \mathrm{~W}^{\wedge} 0.7545 \mathrm{kcal} \text { per day, } \mathrm{W}=\mathrm{g}\right) .
$$

However, upon further inspection, three different periods of energy intake were noted in the 2011 hand-fed chicks. Between day 0 and day 18 of life, the chicks consumed, on average, $1.02 * \mathrm{~W}^{\wedge} 0.7545(\mathrm{~W}=\mathrm{g}) \mathrm{kcal}$ per day, the same as the adult Monk parrot maintenance energy requirement. During days 18-23 of growth, the hand-fed chicks consumed $1.43^{*} \mathrm{~W}^{\wedge} 0.7545(\mathrm{~W}=\mathrm{g}) \mathrm{kcal}$ per day, or 1.4 times adult Monk parrot maintenance energy requirements on average. The possibility exists that this increase in energy needs corresponds to the production of adult feathers. Observations by Caccamise $^{2}$ put the emergence of primary feathers at day 18 with good delineation by day 24 . The head and wing feathers were also fully emerged by day 24 , but many contour feathers on the body were not fully completed until day $37 .^{2} \mathrm{~A}$ similar

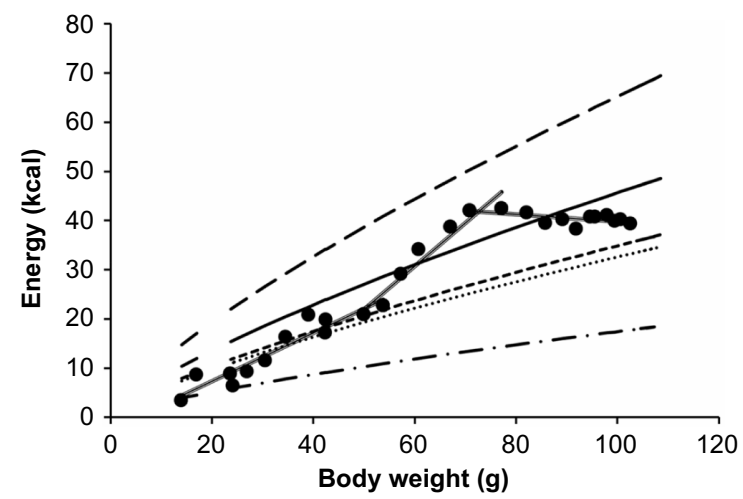

Figure 4 Average energy intake of all birds hand-fed in 2011 compared to energy equations.

Notes: Birds hand-fed in 201 I (filled circles) were compared to one (long dash-dot line) and two times (short dash line) the nonpasserine maintenance energy equation ${ }^{7}$ used to hand-feed $201 \mathrm{I}$ birds; the modified equation represents the adult Monk parrot maintenance energy requirements

$\left(1.87 * 0.5404 * W^{\wedge} 0.7545, W=g\right)$

(I)

(dotted line), I.4 times the adult Monk parrot maintenance energy requirements (solid line), and two times the adult Monk parrot maintenance energy requirements (long dash line). The sets of triple lines through the filled circles show the changes in energy needs as the Monk parrots grew.

increase in energy needs is seen in molting adult birds. Adult White-crowned sparrows (Zonotrichia leucophrys gambelii) at the midpoint of molting use $25 \%-54 \%$ more energy than wintering sparrows. ${ }^{15}$ Additionally, adult European starlings (Sturnus vulgaris) expend 32\% more energy when molting compared to a nonmolting counterpart. ${ }^{16}$ After day 23 , it was observed that the chicks' total energy intake per day remained relatively constant, but the chicks continued to increase their body mass. This suggests that a decrease in the energy requirements of chicks occurs after 23 days of life. Work with chickens by Ricklefs ${ }^{17}$ and long-eared owls (Asio otus) by Wijnandts ${ }^{18}$ suggest this decrease could be due to a decrease in the chick's basal metabolic rate.

The delay in age to reach peak body mass observed for the pink dot, red dot, and 2010 hand-fed birds is likely representative of a slower growth rate for these birds. A delay in maturation may be used by birds in order to prolong the period of growth and attempt to decrease potential detrimental phenotypic effects from nutritional stress. ${ }^{19}$ When Song sparrows were restricted to $60 \%$ of the feed consumed by their counterparts, they took 4-5 more days to reach peak body mass. ${ }^{10}$ The feed-restricted Song sparrows additionally delayed fledging by 1 day compared to the controls. ${ }^{10}$ White-fronted bee-eaters (Merops bullockoides), which have unpredictable feed supplies, are able to delay their normal fledging time (25 days) by 17 days. ${ }^{19}$ Unfortunately, the date of fledging was not recorded in this study. It is also important to note that although the black dot subgroup grew at a faster rate than did the pink dot subgroup, their peak body masses prior to fledging were not different. Thus, growth rate 
is not necessarily indicative of the peak body mass that a bird will attain prior to fledging.

We determined a graphical method of determining the $\mathrm{K}$ constant for use in comparing growth rates between avian species. Using this technique, the $K$ constant for parent-reared Monk parrots was $K=0.1624 .{ }^{1,20}$ Following the same method, the $K$ constant for the average of the chicks hand-fed in 2011 was $K=0.1676$, and similar to the parent-reared chicks. The similar $K$ constant found for the birds hand-fed in 2011 with those that were parent-reared suggests that the 2011 hand-fed birds grew at an acceptable rate. This also suggests that the energy consumed by the 2011 hand-fed birds is similar to the amount the parents provided to their chicks. Thus, our Protocol-2011 (1.02* $\mathrm{Wg}^{\wedge} 0.7545 \mathrm{kcal}$ per day) provided adequate energy through day 18 ( $\sim 54 \mathrm{~g}$ body mass). However, based on increased energy needs for feather development and growth between days 18 and 23, Monk parrot chicks should be provided $1.4 * \mathrm{Wg}^{\wedge} 0.7545 \mathrm{kcal}$ per day during this time.

Energy needs determined in this study changed over the growth period in Monk parrots. Thus, when available, referencing species' growth curves while hand-fed chicks may aid in optimizing their health as adults. Based on the potential health implications from delayed development followed by excessive growth, new information about the growth requirements and caloric needs of Monk parrots and other bird species are needed, especially at the time of fledging and body mass reduction. Additionally, more species-specific and accurate information on hand-fed healthy birds needs to be available to the general population in an easily accessible manner to aid in hand-feeding birds to ensure fledgling survival and optimal long term health.

\section{Proposed Monk parrot growth energy requirements}

Day 0-18: $1.02 * \mathrm{~W}^{\wedge} 0.7545(\mathrm{~W}=\mathrm{g}) \mathrm{kcal}$ per day, and

Day $18-23: 1.43 * \mathrm{~W}^{\wedge} 0.7545(\mathrm{~W}=\mathrm{g}) \mathrm{kcal}$ per day.

\section{Acknowledgments}

The authors would like to thank the Schubot Exotic Bird Health Center at Texas A\&M University for hand feeding the birds used in this study and the Mark L Morris Professorship of Clinical Nutrition for its support of the study. The authors would additionally like to thank Rick Jordan of Hill Country Aviaries for sharing knowledge of hand-fed psittacine birds. The authors would also like to thank all the individuals at Texas A\&M University who aided in hand-feeding the Monk parrots in this report, Elizabeth Bellinger for data entry and, finally, Janet Reed for providing a new start for many Monk parrots.

\section{Disclosure}

The authors report no conflicts of interest in this work.

\section{References}

1. Caccamise DF, Alexandro PJ. Growth rate in the Monk parakeet. Wilson Journal of Ornithology. 1976;88(3):495-497.

2. Caccamise DF. Growth and development of major body components in the Monk parakeet. Wilson Bulletin. 1980;92(3):376-381.

3. Orosz SE. Clinical Avian Nutrition. Vet Clin North Am Exot Anim Pract. 2014;17(3):397-413.

4. Subcommittee on Dog and Cat Nutrition, Committee on Animal Nutrition, Board on Agriculture and Natural Resources, Division on Earth and Life Studies, National Research Council. Nutrient Requirements of Dogs and Cats. Washington, DC: The National Academies Press; 2006.

5. Heatley JJ, Cornejo J. Psittaciformes. In: Miller RE and Fowler ME, editors. Fowler's zoo and wild animal medicine. Elsevier Health Sciences. 2014;8:172-186.

6. Kaytee [webpage on the Internet]. Hand feeding. Chilton, WI: Kaytee Products, Inc., Central Garden and Pet; 2013. Available from: http:// www.kaytee.com/pet-birds/general-care/hand-feeding.htm. Accessed July 30, 2011

7. Kendeigh SC. Energy requirements for existence in relation to size of bird. The Condor. 1970;72(1):60-65.

8. Schew WA, Ricklefs RE. Developmental plasticity. In: Stark JM, Ricklefs RE, editors. Avian Growth and Development. Evolution Within the Altricial-Precocial Spectrum. New York, NY: Oxford University Press; 1998:288-304.

9. Metcalfe NB, Monaghan P. Compensation for a bad start: grow now, pay later? Trends Ecol Evol. 2001;16(5):254-260.

10. Searcy WA, Peters S, Nowicki S. Effects of early nutrition on growth rate and adult size in song sparrows Melospiza melodia. Journal of Avian Biology. 2004;35:269-279.

11. Ricklefs RE. Weight recession in nestling birds. The Auk. 1968;85(1): 30-35.

12. Slining M, Adair LS, Goldman BD, Borja JB, Bentley M. Infant overweight is associated with delayed motor development. J Pediatr. 2010; 157(1):20-25. e1.

13. Nowicki S, Searcy WA, Peters S. Brain development, song learning and mate choice in birds: a review and experimental test of the "nutritional stress hypothesis". J Comp Physiol A Neuroethol Sens Neural Behav Physiol. 2002;188(11-12):1003-1014.

14. Petzinger C. Lipid Metabolism, Learning Ability and Potential Biomarkers for Atherosclerosis in Monk Parrots (Myiopsitta monachus) Fed n-3 Fatty Acids [dissertation]. College Station, TX: A\&M University; 2012.

15. Schieltz PC, Murphy ME. The contribution of insulation changes to the energy cost of avian molt. Can J Zool. 1997;75(3):396-400.

16. Cyr NE, Wikelski M, Romero LM. Increased energy expenditure but decreased stress responsiveness during molt. Physiol Biochem Zool. 2008;81(4):452-462.

17. Ricklefs RE. Energetics of reproduction in birds. In: Paynter RA Jr, editor. Avian Energetics. Cambridge, MA: Nuttall Ornithological Club; 1974:152-292.

18. Wijnandts H. Ecological energetic of the long-eared owl (Asio otus). Ardea. 1984;72:1-92.

19. Emlen ST, Wrege PH, Demong NJ, Hegner RE. Flexible growth rates in nestling white-fronted bee-eaters: a possible adaptation to short-term food shortage. The Condor. 1991;93(3):591-597.

20. Ricklefs RE. A graphical method of fitting equations to growth curves. Ecology. 1967;48(6):978-983. 
Veterinary Medicine: Research and Reports

Dovepress

\section{Publish your work in this journal}

Veterinary Medicine: Research and Reports is an international, Visit http://www.dovepress.com/testimonials.php to read real quotes peer-reviewed, open access journal publishing original research,

case reports, editorials, reviews and commentaries on all areas of

veterinary medicine. The manuscript management system is completely online and includes a very quick and fair peer-review system.

from published authors.

Submit your manuscript here: http://www.dovepress.com/veterinary-medicine-research-and-reports-journal 